\title{
Textile Design and Draping
}

\section{Zrinka Tomašić*}

Department of Fashion and Textile Design, Faculty of Textile Technology, University of Zagreb, Croatia

Draping is the oldest known form of making clothes, cave man have draped some hides around his body to make him worm. Afterwards it came sewing.

Draping is present through all history of mankind until present. There are various examples of draped garments like chitons, loinclothes, togas, stolas, saris, sarongs, pareos, dhotis, ponchos, cloaks, shawls, in matter of fact you can drape any kind of textile material that is long

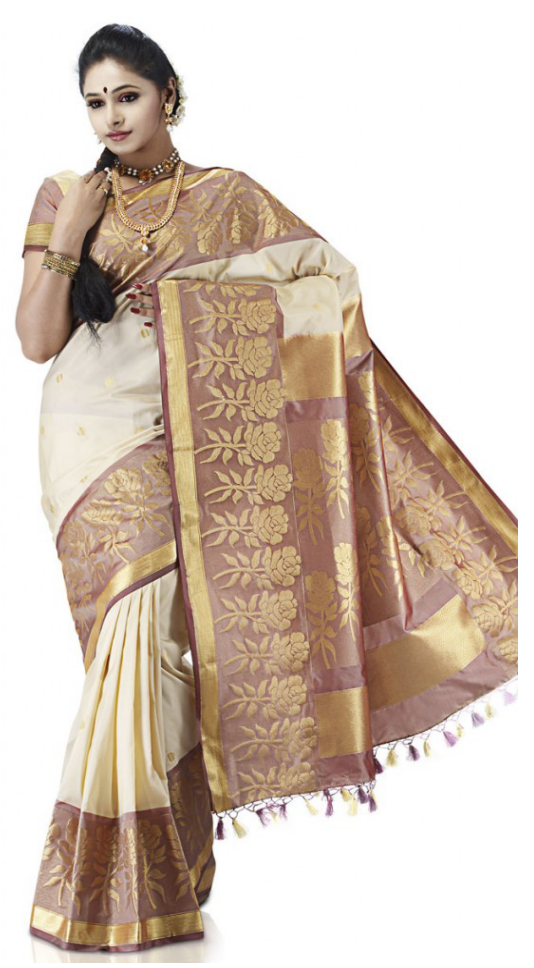

Figure 1: A picture of traditional sari.

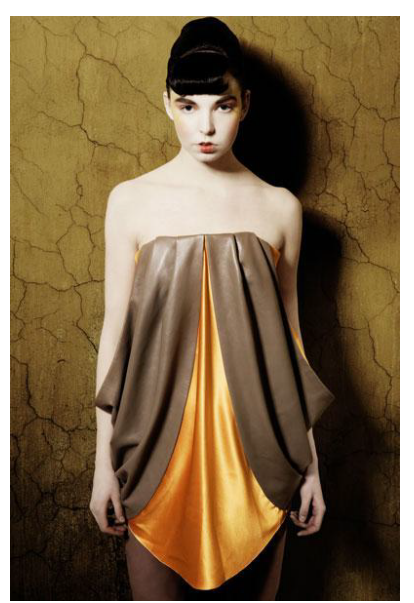

Figure 2: A picture of Christina Lovery's drape leather and silk. enough for the purpose you want to use it. We are getting the new look every time draping the various textile clothes in several manners.

In this sense, can we combine textile design and draping? Sure we can. If the textile design is put on the right place in the draping process, we can obtain the most preminent design.

As we can see that on Figure 1 (a picture of traditional sari). On this traditional, yet contemporary garment, the textile design is carefully combined with the draping technique to obtain good and effective appearance. Excellent textile design with excellent darping provides excellent results. Draped garment combining perfect textile design is most effective even, in my opinion, at western gala-events. You can choose it to outstand the others.

As it can be seen on Figure 2 and 3 (a picture of Christina Lovery's drape leather and silk), combining of two different textile materials with different properties can be rather interesting choice. On this modern garment is combined draping with interjoining methods. This textile materials although they diverse one from another, are having some similarities like lustre. These differences and similiraties alongside the draping technique and interjoining technique are obtaining the most exclusive overall design.

As it show in Figure 3 (figure of traditional sari), draping can stand alone with one kind of designed textiles or it can be comined with interjoining technicques and obtained with different kind of textiles bond togethet (Figures 2 and 3 of modern clothing). All these combining makes draping one of the most interesting aspects of design.

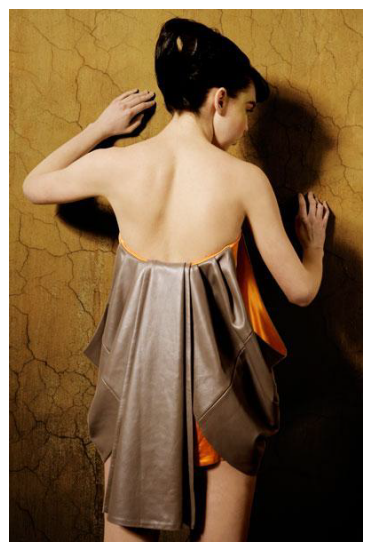

Figure 3: Draping-stand alone with one kind of designed textiles

*Corresponding author: Zrinka Tomašić, Department of Fashion and Textile Design, Faculty of Textile Technology, University of Zagreb, Croatia, E-mail: zrinka.tomasic@outlook.com

Received November 04, 2013; Accepted November 05, 2013; Published November 10, 2013

Citation: Tomašić Z (2013) Textile Design and Draping. J Textile Sci Eng 3: 143. doi:10.4172/2165-8064.1000143

Copyright: (c) 2013 Tomašić Z. This is an open-access article distributed under the terms of the Creative Commons Attribution License, which permits unrestricted use, distribution, and reproduction in any medium, provided the original author and source are credited. 